\section{Characterization of plastic degrading bacteria isolated from landfill sites}

\author{
Afreen Bakht ${ }^{1}$, Nouman Rasool ${ }^{2 *}$ and Saima Iftikhar ${ }^{3}$ \\ ${ }^{1}$ Department of Life Science, University of Management and Technology, Lahore, Pakistan \\ ${ }^{2}$ Center for Professional Studies, Lahore, Pakistan \\ ${ }^{3}$ School of Biological Sciences, University of the Punjab, Lahore, Pakistan
}

\begin{abstract}
The plastic pollution is threatening the environment because it has very slow degradation rate and high usage in regular activities. The present study aims at the isolation of novel microorganisms that would assist faster degradation process of polyethylene. The waste samples were collected from different landfills and dumpsites. Out of forty samples, eight samples were found to degrade polythene strips in liquid medium. Further screening of these samples showed that two strains of microbes had high potential for polythene degradation. Biochemical tests and ribotyping were performed for characterization of isolated bacteria. Resultantly, two novel bacterial strains were identified named; Bacillus wudalianchiensis_UMT (2A) and Pseudomonas aeruginosa UMT (6). Analysis of these microbes further revealed that Bacillus wudalianchiensis_UMT and Pseudomonas aeruginosa_UMT have capability to degrade $6.6 \%$ and $4.8 \%$ polyethylene respectively. So, the results disclosed that these bacteria have great potential to degrade polythene in less time as compare to natural degradation process and can contribute to reduce pollution from our environment.
\end{abstract}

\author{
More Information \\ *Address for Correspondence: Nouman \\ Rasool, Center for Professional Studies, Lahore \\ Pakistan, Email: alimuhd4real@gmail.com \\ Submitted: 16 April 2020 \\ Approved: 27 May 2020 \\ Published: 28 May 2020 \\ How to cite this article: Bakht A, Rasool N, \\ Iftikhar S. Characterization of plastic degrading \\ bacteria isolated from landfill sites. Int $\mathrm{J}$ Clin \\ Microbiol Biochem Technol. 2020; 3: 030-035 \\ DOI: 10.29328/journal.ijcmbt.1001013
}

Copyright: (c) 2020 Bakht A, et al. This is an open access article distributed under the Creative Commons Attribution License, which permits unrestricted use, distribution, and reproduction in any medium, provided the original work is properly cited

Check for updates

OPEN ACCESS

\section{Introduction}

The use of plastic is growing day by day. Its durability and stability has made it an indispensable part of our life. Despite its superiority over other materials, it is posing a major threat to the environment because these long chain polymeric molecules take thousand years to decompose naturally. According to UNDP, more than 3.3 million tons of plastic are wasted in Pakistan each year. So, it is a much needed step to reduce its lifespan in order to protect the environment. Biodegradation is an environmental friendly method to degrade polyethylene as it does not generate any harmful byproducts. The speed of degradation depends upon the chemical nature of polymer, on the environmental conditions in which it is placed and on the amount of polymer. Statistically stated, $38 \%$ plastic is used for packaging and this rate of utilization is increasing $12 \%$ every year. $12 \%$ plastic is used for construction, $21 \%$ for indoors and the outdoors, $7 \%$ for automotive, $6 \%$ for electronics and $28 \%$ plastic is used in other sectors. When these plastics are introduced into the environment, they cause potential hazards [1]. Though, plastic is useful in many applications but it poses serious effect to the environment. Because plastic is durable that's why it is highly persistent to decay. There is chemical bonding in its molecules which make is resilient to degrade. Plastic takes hundreds of years to degrade naturally [2].
Statistical data of worldwide consumption of plastic shows that North America utilizes 26\%, Europe 23\%, India 5\%, Japan $6 \%$ and Asia contributes $40 \%$ of total plastic consumption in the world. Plastic can be disposed by different methods like incineration, landfills and through process of recycling. There are benefits and limitations in each case. When plastic waste is disposed in landfills, it apparently reduces wastes from upper surface of land but in true terms it reduces the land for agriculture [3]. As it takes so many years to degrade it naturally, so the area of landfill cannot be used for other purpose [4]. Incineration is a better option as compared to the landfills as it does not require much space and it is also better in terms of energy recovery [5]. However, it is not beyond the limitations because it causes greenhouse gases and it is also responsible for PCBs and free radical exposure [6]. Regardless of this, the limitations of landfills and incineration can be overcome through recycling though this process is expensive and the quality of end products is also low [7].

Biodegradation is the best methods as compare to the others. It is cheap and does not generate harmful pollutants into the environment. Plastic can be degraded through microorganisms. Thus, microbes play an important role in degradation process [8]. 


\section{Materials and methods}

\section{Sample collection}

Forty soil samples were collected from different dumpsites and landfills from Lahore and Bhera (Pakistan) with the help of sterilized spatula and were stored in polythene bags. Each sample was given a specific ID.

\section{Screening of microbes having ability to degrade plastic}

Flasks of $5 \mathrm{ml}$ liquid broth were prepared. $10 \mathrm{mg}$ soil of each sample was put in every flask. All flasks were kept in shaker overnight to get maximum growth of microbes [9]. Took $1 \mathrm{ml}$ from primary inoculums and was put in $150 \mathrm{ml}$ enriched media. This enriched media was composed of yeast extract $0.1 \mathrm{~g}, \mathrm{MgSO}_{4} \cdot \mathrm{H}_{2} \mathrm{O}, 0.25 \mathrm{~g} ; \mathrm{KH}_{2} \mathrm{PO}_{4}, 5.8 \mathrm{~g} ; \mathrm{K}_{2} \mathrm{HPO}_{4} 3.7 \mathrm{~g} ; \mathrm{KNO}_{3}, 2.0 \mathrm{~g}$ in $1000 \mathrm{ml}$ of distilled water. $100 \mathrm{mg}$ LMWPE strips were put in each enriched media flask. These flasks were then autoclaved. After that, flasks were kept in shaker for seven days. During seven days all other microbes died except of those who had capacity to degrade polymer [10]. Agar plates were prepared from enriched media by using three different substrates to examine the efficiency of microbes in each substrate. The used substrates were consisted of $1 \mathrm{~g}$ Polyethylene glycol (PEG), mixture of $200 \mu \mathrm{l}$ hexadecane and $20 \mu \mathrm{l}$ Tween 80 and $100 \mathrm{mg}$ plastic powder [11].

\section{Methods for screening of microbes}

Clear zone method: Emulsified agar plates having substrate were streaked by dipping the L shaped loop in enriched median flasks which were previously inoculated in shaker for seven days. These plates were kept in incubator at $37^{\circ} \mathrm{C}$ for seven days. After seven days, the diameter of clear zone around the colonies was observed and measured [12].

Determination of weight loss: The pre weighed plastic strips were removed from the flaks. These strips were rinsed thoroughly once with distilled water and then with absolute ethanol in order to remove the impurities. Strips were over dried at $90{ }^{\circ} \mathrm{C}$. The weight was determined by using the following formula [13]:

$$
\text { Weight } \operatorname{loss}(\%)=\frac{\text { InitialWeight }- \text { Final Weight }}{\text { Initial Weight }} \times 100
$$

\section{Sequencing}

After isolation of genomic DNA, PCR was run for those eight samples. Universal primers 16S rRNA (5'-AAACTC/ TAAAG/TGAATTGACGG-3') and (5'-ACGGGCGGGTGTGTA/GC3 ') were used. The PCR product was analysed on 1\% agarose gel and purified using gel extraction kit (Fermentas, USA). M13 forward and reverse primers were used to sequence the rRNA amplified products in a Beckman Coulter CEQTM 8000 Genetic Analyser. National Centre for Biotechnology Information BLAST database was used to amplify nucleotide sequence. These sequences were aligned with selected genera representative members by using CLUSTAL W program [14]. After sequencing, two samples $(2 \mathrm{~A}, 6)$ were preceded further which had high potential to degrade plastic more and which had new strains.

\section{Quantification of DNA}

After isolation, the genomic DNA was quantified at $260 \mathrm{~nm}$ using UV-1280 Spectrophotometer using water as blank. Liquid media was inoculated with bacterial colonies and kept in shaker at $37^{\circ} \mathrm{C}$ for overnight. After 16 hours, $1 \mathrm{ml}$ culture from overnight media was taken and put in $50 \mathrm{ml}$ media flask. The flasks were then kept in shaker and readings were taken after every two hours [15].

\section{Effect of temperature on growth}

The isolated bacterial strains were grown at temperature $37^{\circ} \mathrm{C}, 45^{\circ} \mathrm{C}, 50^{\circ} \mathrm{C}$ and $60^{\circ} \mathrm{C}$ to determine the temperature for optimal growth. After seven hours, the absorbance was assessed at $260 \mathrm{~nm}$ by using spectrophotometer [16].

\section{Phylogenetic tree}

The sequenced 16S rRNAs amplified from both bacterial strains were compared with sequences available in nucleotide databases. Pseudomonas aeruginosa_UMT sequence was used as out group for Bacillus strains and Bacillus wudalenchinesis_ UMT sequence was used as an out group for Pseudomonas aeruginosa. Best fit model was deduced and was implemented to draw phylogenetic tree.

\section{Identification tests for microbes}

Preliminary tests: Gram staining method: This is a widely used method in bacteriology. In this method, a slide was used which was grease free and clean. A smear from bacterial culture was spread in this slide by using a sterilized loop. This slide is then fixed with the heat and was passed by staining reagents [17].

Hanging drop method: This is a motility test which is used to observe live microbes and their mobility. A drop was placed on the cover slip to observe microbes in this drop and was covered by the cavity slide. Microbes in droplet were observed under light microscope [18].

\section{Biochemical tests}

Catalyze test: Culture sample was placed on the slide and then hydrogen peroxide was added on the slide drop by drop. Samples which showed bubble formation indicated positive results [19].

Motility test: The mobility test of both isolated strains was performed in semi-solid agar medium containing $0.4 \mathrm{~g}$ agar, $2 \mathrm{mg}$ peptone and $1 \mathrm{~g} \mathrm{NaCl}$ in $200 \mathrm{ml}$ of distilled water. The sterilized straight wire was used to inoculate the culture in a single stab centrally from top to bottom of the medium. The incubation of tube was carried out at $30^{\circ} \mathrm{C}$ for overnight. A diffused hazy growth represented motile bacterium, spread throughout the medium. 


\section{Caesin hydrolysis}

In this method a loop was used to transfer culture on the agar plate. Plates were inverted and kept in incubator for one to two days [20].

\section{Gelatin hydrolysis}

Suspension was prepared from overnight culture media. This suspension is then pipette in two tubes that contained gelatin agar base. Both of these tubes were kept in incubator at $37^{\circ} \mathrm{C}$. One tube was tested after 4 hours and one tube was tested after 24 hours. Acid was added and reading was recording after 30 minutes against blank gelatin agar tube.

\section{Urea broth}

In this method equal volume of urea buffer and suspension were mixed. Capillary tubes were incubated at $37^{\circ} \mathrm{C}$ and alkali production was recorded after 4 and 24 hours [21].

\section{Oxidase test and mannitol test}

The smear of a colony of isolated bacterium was introduced on a filter paper containing few drops of oxidase reagent $(0.1$ $\mathrm{g}$ of tetramethyl-p-phenylenediamine dihydrochloride in 100 $\mathrm{ml}$ of distilled water). The colony having oxidase activity, gave a characteristic color. In order to check the ability of isolated bacteria for fermenting mannitol, phenol red mannitol broth with $0.5 \%-1.0 \%$ mannitol was used. Single colony of each isolated bacterium was incubated at $37^{\circ} \mathrm{C}$ for 24 hours. The change in color from red to yellow indicated that bacteria have ability to ferment mannitol.

\section{Results and discussion}

Total forty samples were collected from different dumpsites and landfill sites of Bhera and Lahore respectively. Out of which only nine samples showed positive results i.e. reduction in weight loss (Table 1 ).

\section{Plate assay showing plastic degradation by microbes}

Culture flasks in which weight of strips were reduced was streaked on nutrient agar plates in which PEG as substrate was added previously. After seven days of incubation, clear zones were observed around single colony having PEG substrate (Figure 1).

\section{Isolation of genomic DNA from microbes}

After isolation, the quality and quantity of genomic DNA was analyzed on 1\% agarose gel (Figures 2,3).

\section{Gel of gene clean}

After PCR, gene clean was done. Six samples were run for gene clean on agarose gel. After running these samples on agarose gel, positive results were seen in all samples (Figure 4).

\section{Ribotyping}

After gene clean, ribotyping was done in which nucleotides sequences of isolated bacteria were used to analyze through NCBI BLAST database. The homology was determined by aligning the multiple sequences through CLUSTAL W program. Sequencing was done for all samples, out of which sample 2A and sample 6 had new strains.

\begin{tabular}{|c|c|c|c|c|}
\hline \multicolumn{6}{|c|}{ Table 1: Loss of weight of plastic by isolated microbes. } \\
\hline Serial No & Sample ID & Final weight & Initial weight & Weight loss (\%) \\
\hline 1 & $1 \mathrm{~A}$ & 96.6 & $100 \mathrm{mg}$ & 3.4 \\
\hline 2 & $2 \mathrm{~A}$ & 93.6 & $100 \mathrm{mg}$ & 6.4 \\
\hline 3 & $8 \mathrm{~A}$ & 96.3 & $100 \mathrm{mg}$ & 3.7 \\
\hline 4 & $8 \mathrm{~B}$ & 97.7 & $100 \mathrm{mg}$ & 2.3 \\
\hline 5 & 6 & 95.7 & $100 \mathrm{mg}$ & 4.3 \\
\hline 6 & $\mathrm{~N} 6$ & 99 & $100 \mathrm{mg}$ & 1 \\
\hline 7 & N7(i) & 97 & $100 \mathrm{mg}$ & 3 \\
\hline 8 & N7(ii) & 98.5 & $100 \mathrm{mg}$ & 1.5 \\
\hline 9 & N9 & 99 & $100 \mathrm{mg}$ & 1 \\
\hline
\end{tabular}

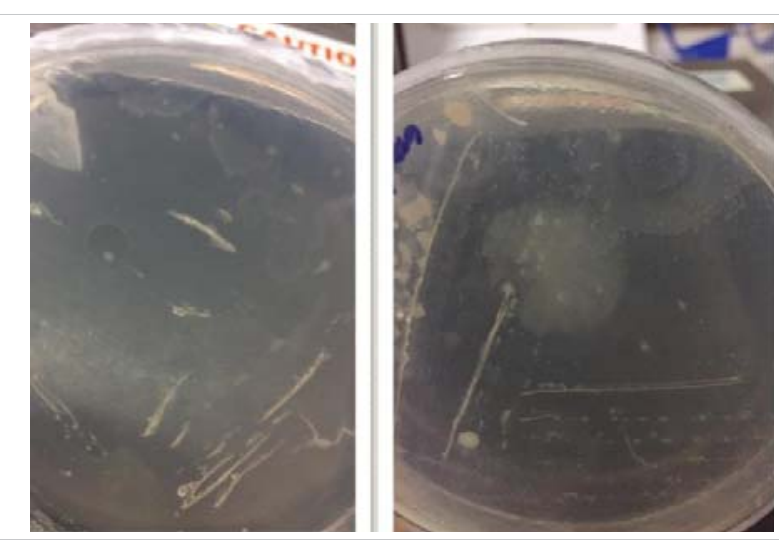

Figure 1: Formation of enriched zones by microbes.

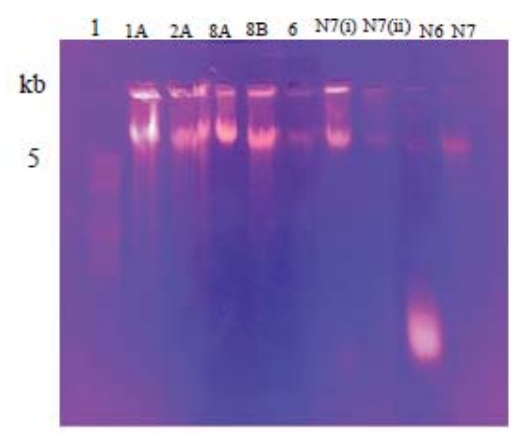

Figure 2: Ethidium Bromide stainedAgarose gel showing genomic DNA isolate from different strains. Lanes $1 A, 2 A, 8 A, 8 B, 6, N 7$. (i) showing bands of polyethylene degrading strains but very weak bands in lane N7. (ii), N6 and N9. Lane 1 is showing DNA marker.

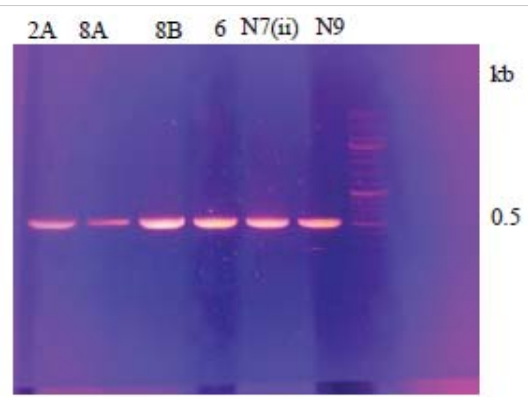

Figure 3: Ethidium Bromide stained Agarose gel showing PCR product from different strains. Lane 1 is showing ladder and lanes $2 \mathrm{~A}, 8 \mathrm{~A}, 8 \mathrm{~B}, 6, \mathrm{~N} 7$ (ii) and N9 showing amplified PCR product of $0.5 \mathrm{~kb}$. 


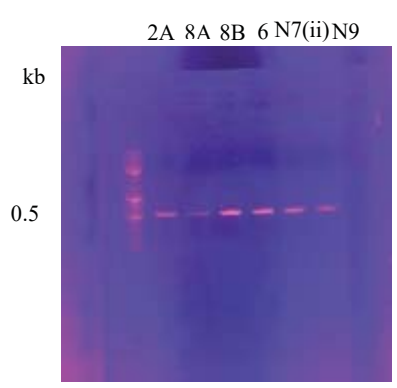

Figure 4: Ethidium Bromide stained Agarose gel showing DNA purification ge from different samples. Lane 1 is showing ladder and lanes $2 \mathrm{~A}, 8 \mathrm{~A}, 8 \mathrm{~B}, 6, \mathrm{~N} 7$ (ii) and N9 showing bands of gene clean of $0.5 \mathrm{~kb}$.

Bacillus Sp. (Sample 2A):

CATGTGGTTTATTCGAAGCAACGCGAAGAACCTTACCAGGT CTTGACATCCCGCTGACCGGTCTGGAGACARATCTTTCCCTTCG GGGACAGCGGTGACAGGTGGTYCATGGTTGTCGTCAGCTCGTG TCGTGAGATGTTGGGTTAAGTCCCGCAACGAGCGCAACCC TTGATCTTAGTTGCCAGCATTCAGTTGGGCACTCTAAGGT GACTGCCGGTGACAAACCGGAGGAAGGTGGGGATGACGTCAAA TCATCATGCCCCTTATGACCTGGGCTACACACGTGCTACAATG GATGGTACAAAGGGCTGCAAGACCGCAAGGTTTAGCCAATCCC ATAAAACCATTCTCAGTTCGGATTGCAGGCTGCAACTCGCCTG CATGAAGCCGGAATCGCTAGTAATCGCGGATCAGCATGCCGCG GTGAATACGTTCCCGGGCCTTGWACACACCGCCCRAAA.

Pseudomonas Sp. (Sample N9):

CATGTGGTTTATTCGAGCAACGCGAAGAACCTTACCTGG ССTT $\backslash$ GACATGCTGAGAACTTTCCAGAGATGGATTGGKGCCTT CGGGAACTCAGACACAGGTGCTGCWTGGCTGTCGTCAGCTCG TGTCGTGAGATGTTGGGTTAAGTCCCGTAACGAGCGCAACCC TTGTCCTTAGTTACCAGCACCTCGGGTGGGCACTCTAAGGAGA CTGCCGGTGACAAACCGGAGGAAGGTGGGGATGACGTCAA GTCATCATGGCCCTTACGGCCAGGGCTACACACGTGCTACAATG GTCGGTACAAAGGGTTGCCAAGCCGCGAGGTGGAGCTAATCC CATAAAACCGATCGTAGTCCGGATCGCAGTCTGCAACTCGA CTGCGTG AAGTCGGAATCGCTAGTAATCGTGAATCAGAATGTCA CGGTGAATACGTTCCCGGGCCTTGTACACACCGCCCGT.

In vitro degradation of plastic by Pseudomonas aeruginosa_UMT and Bacillus wudalianchiensis UMT:

After sequencing new bacterial strains were identified that were Bacillus wudalianchiensis_UMT (2A) and Pseudomonas aeruginosa_UMT (6). The seven days experiment was repeated again that was explained previously for the confirmation of their weight reduction potential (Figure 5) (Table 2).

\section{Effect of temperature on growth}

The growth temperature of the Bacillus wudalianchiensis UMT and Pseudomonas aeruginosa_UMT ranged from $37^{\circ} \mathrm{C}$ to $60^{\circ} \mathrm{C}$. Growth stopped above $60^{\circ} \mathrm{C}[22]$ (Figure 6) (Tables 3,4).

\section{Biochemical characterization}

Bacillus wudalianchiensis_UMT exhibited catalase, caesin
Hydrolysis, Gelatin Hydrolysis and Urea broth activities. It indicated negative results for the tests of oxidase, mannitol and hanging drop method. Pseudomonas aeruginosa_UMT showed positive results for oxidase, mannitol, catalase, caesin hydrolysis, gelatin hydrolysis, urea broth activities and hanging drop method [23].

Phylogenetic tree of Bacillus wudalianchiensis_UMT: The phylogenetic tree was constructed using amplified 16S rRNA from both bacteria, sequenced and comparing with those in nucleotide databases. Pseudomonas aeruginosa_UMT was used as an out group for Bacillus wudalianchiensis UMT. Phylogenetic tree gives a clear indication that there is homology between different strains of Pseudomonas Sp. It is clear from phylogenetic tree that sample $2 \mathrm{~A}$ is close in cluster with Bacillus wudalianchiensis_UMT. Each name at the wudalianchiensis_UMT (Figure 7).

Phylogenetic tree of Pseudomonas aeruginosa_UMT: Bacillus wudalianchiensis_UMT was used as an out-group for Pseudomonas aeruginosa. The phylogenetic tree shows that there is $90 \%$ homology between different strains of Pseudomonas (Figure 8) .

\section{Conclusion}

The increase in use of plastic is growing concern and major contributor to pollution across the globe. Scientists are working to develop environmental friendly methods to degrade the plastic causing pollution. Different microbes has been identified having the potential to degrade polythene

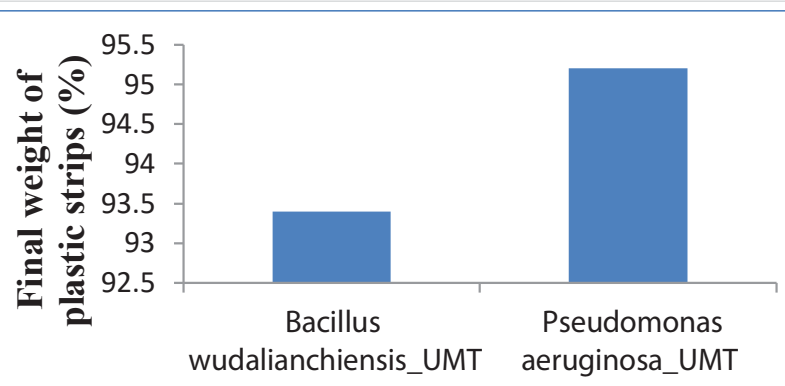

Samples

Figure 5: Graph showing comparison of final weight of both samples.

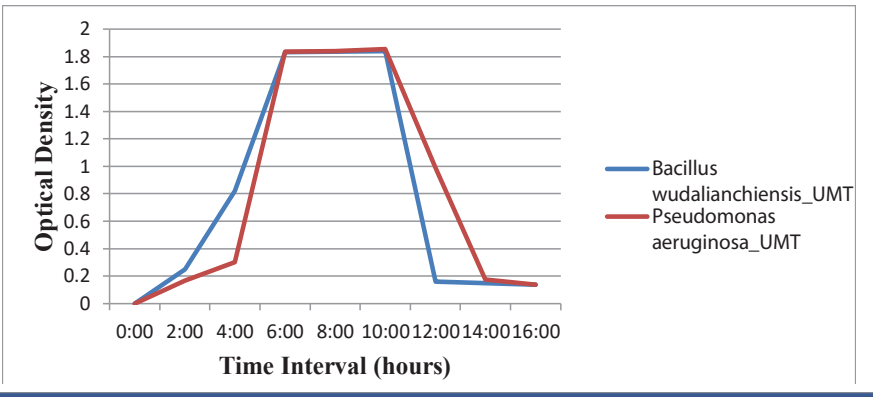

Figure 6: Growth comparison of Bacillus wudalianchiensis_UMT and Pseudomonas aeruginosa UMT on different time intervals at $37^{\circ} \mathrm{C}$. The growth curve indicates maximum growth at 10 hours after which it starts decreasing 
Table 2: Percentage of weight loss by Bacillus wudalenchinesis_UMT (2A) and Pseudomonas aeruginosa_UMT (6):

\begin{tabular}{|c|c|c|c|c|}
\hline Serial No & Sample ID & $\begin{array}{c}\text { Final weight } \\
(\mathbf{m g})\end{array}$ & $\begin{array}{c}\text { Initial weight } \\
(\mathbf{m g})\end{array}$ & $\begin{array}{c}\text { Percentage of weight } \\
\text { lose (\%) }\end{array}$ \\
\hline 1 & $2 \mathrm{~A}$ & 93.4 & $100 \mathrm{mg}$ & 6.6 \\
\hline 2 & 6 & 95.2 & $100 \mathrm{mg}$ & 4.8 \\
\hline
\end{tabular}

Table 3: Determination of optimum growth of Bacillus wudalenchinesis_UMT(2A) at different temperatures.

\begin{tabular}{|c|c|c|}
\hline Serial No & Temperature & Maximum OD at $\mathbf{2 6 0} \mathbf{~ n m}$ \\
\hline 1 & $37^{\circ} \mathrm{C}$ & 1.839 \\
\hline 2 & $45^{\circ} \mathrm{C}$ & 0.239 \\
\hline 3 & $50^{\circ} \mathrm{C}$ & 0.342 \\
\hline 4 & $60^{\circ} \mathrm{C}$ & 0.34 \\
\hline
\end{tabular}

Table 4: Determination of optimum growth of Pseudomonas aeruginosa_UMT(6) at different temperatures

\begin{tabular}{|c|c|c|}
\hline Serial No & Temperature & Maximum OD at $\mathbf{2 6 0} \mathbf{~ n m}$ \\
\hline 1 & $37^{\circ} \mathrm{C}$ & 1.99 \\
\hline 2 & $45^{\circ} \mathrm{C}$ & 0.38 \\
\hline 3 & $50^{\circ} \mathrm{C}$ & 0.224 \\
\hline 4 & $60^{\circ} \mathrm{C}$ & 0.038 \\
\hline
\end{tabular}

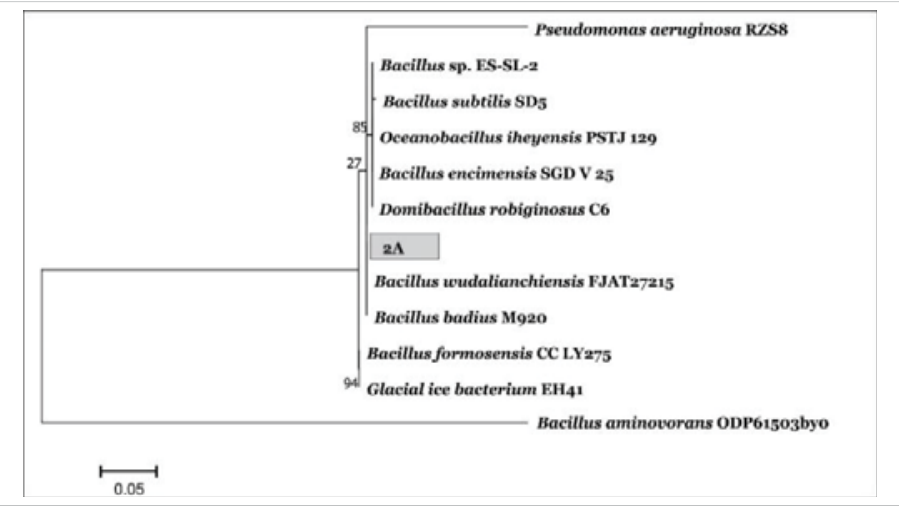

Figure 7: A phylogenetic tree of Bacillus_UMT (2A) showing relationships between $16 \mathrm{~S}$ rRNA sequences.

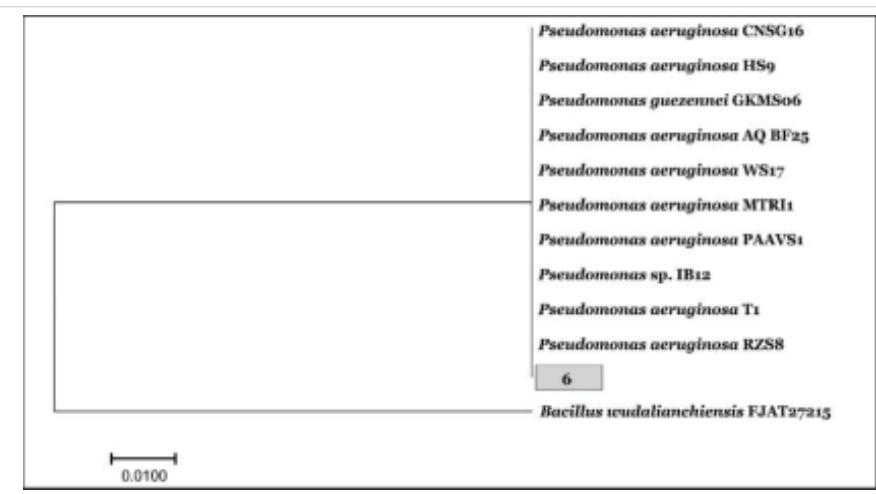

Figure 8: A phylogenetic tree of sample Pseudomonas aeruginosa_UMT (6) showing relationships between $16 \mathrm{~S}$ rRNA sequences.

and other plastics. This study is aimed at isolation and characterization of plastic degrading bacterial from landfill sites. Samples from landfill sites were used to isolate different bacteria having ability to degrade plastic. Two bacterial strains have shown great potential to degrade plastic with substantial growth in culture media. On the basis of biochemical tests and phylogenetic tree it was revealed that these two bacteria are
Bacillus wudalianchiensis_UMT and Pseudomonas aeruginosa_ UMT. Bacillus wudalianchiensis_UMT degraded $6.6 \%$ plastic and Pseudomonas aeruginosa_UMT degraded $4.8 \%$ in culture media. We concluded that these two bacteria are suitable to be used at large scale for degrading plastic at landfill sites and in industries to degrade plastics. In future studies, the cloning and expression of plastic degrading genes can be done.

\section{References}

1. Kint $D$, Muñoz-Guerra S. A review on the potential biodegradability of poly (ethylene terephthalate). Polymer Int. 1999; 48: 346-352.

2. Shaw DK, Sahni P. Plastic to oil. J Mechan Civil Engineering. 2004; 46-48.

3. Zhang J, Wang X, Gong J, Gu Z. A study on the biodegradability of polyethylene terephthalate fiber and diethylene glycol terephthalate. $\mathrm{J}$ Applied Polymer Sci. 2004; 93: 1089-1096.

4. Tansel B, Yildiz BS. Goal-based waste management strategy to reduce persistence of contaminants in leachate at municipal solid waste landfills. Environment, Development and Sustainability. 2001; 13: 821-831.

5. Sinha V, Patel MR, Patel JV. PET waste management by chemical recycling: a review. J Polymers Environ. 2010; 18: 8-25.

6. Astrup T, Møller J, Fruergaard T. Incineration and co-combustion of waste: accounting of greenhouse gases and global warming contributions. Waste Manag Res. 2009; 27: 789-799. PubMed: https://www.ncbi.nlm.nih.gov/pubmed/19748939

7. Yamada-Onodera $\mathrm{K}$, Mukumoto $\mathrm{H}$, Katsuyaya $\mathrm{Y}$, Saiganji A, Tani $\mathrm{Y}$. Degradation of polyethylene by a fungus, Penicilliumsimplicissimum YK. Polymer Degradation and Stability. 2001; 72: 323-327.

8. Head IM, Swannell, RP. Bioremediation of petroleum hydrocarbon contaminants in marine habitats. Curr Opin Biotechnol. 1999; 10: 234-239. PubMed: https://www.ncbi.nlm.nih.gov/pubmed/10361073

9. Santhini K, Myla J, Sajani S, Usharani G. Screening of Micrococcus $\mathrm{sp}$ from oil contaminated soil with reference to bioremediation. Botany Res Int. 2009; 2: 248-252.

10. Yoon MG, Jeon HJ, Kim MN. Biodegradation of polyethylene by a soil bacterium and AlkB cloned recombinant cell. J Bioremed Biodegrad. 2012; 3: 1-8.

11. Kim MN, Park ST. Degradation of poly (L-lactide) by a mesophilic bacterium. J Appl Polymer Sci. 2010; 117: 67-74.

12. Augusta J, Müller RJ, Widdecke HA. A rapid evaluation plate-test for the biodegradability of plastics. Appl Microbiol Biotechnol. 1993; 39: 673-678.

13. Usha R, Sangeetha T, Palaniswamy M. Screening of polyethylene degrading microorganisms from garbage soil. Libyan Agri Res Center J Int. 2011; 2: 200-204.

14. Kwon SW, Kim JS, Park IC, Yoon SH, Park DH, et al. Pseudomonas koreensis sp. nov, Pseudomonas umsongensis sp. nov. and Pseudomonas jinjuensis sp. nov, novel species from farm soils in Korea. Int J Syst Evol Microbiol. 2003; 53: 21-27. PubMed: https://www.ncbi.nlm.nih.gov/pubmed/12656147

15. Rasool N, Rashid N, Javed MA, Haider MS. Requirement of propeptide in proper folding of subtilisin-like serine protease TK0076. Pak J Bot. 2011; 43: 2059-2065.

16. Kapri A, Zaidi MGH, Satlewal A, Goel R. SPION-accelerated biodegradation of low-density polyethylene by indigenous microbial consortium. Int Biodeterio Biodegrad. 2010; 64: 238-244. 
17. Jalal A, Rashid N, Rasool N, Akhtar M. Gene cloning and characterization of a xylanase from a newly isolated Bacillus subtilis strain R5. J Bioscience Bioengineering. 2009; 107: 360-365.

18. Vignesh R, Deepika RC, Manigandan P, Janani R. Screening ofdegrading microbes from various dumped soil samples. Int Res J Engineering Technol. 2016; 4: 2493-2498.

19. Ribón W. Biochemical isolation and identification of mycobacteria. In Biochemical Testing. InTech. 2012.

20. Brown A, Smith H. Benson's Microbiological Applications, Laboratory Manual in General Microbiology, Short Version. McGraw-Hill Science/ Engineering/Math. 2014.
21. Del Valle LJ, Jaramillo ML, Talledo M, Pons MJ, Flores $L$, et al. Development of a 16S rRNA PCR-RFLP assay for Bartonella identification: applicability in the identification of species involved in human infections. Uni J Microbiol Res. 2014.

22. Munna MS, Tahera J, Afrad MMH, Nur IT, Noor R. Survival of Bacillus spp. SUBB01 at high temperatures and a preliminary assessment of its ability to protect heat-stressed Escherichia coli cells. BMC Res Notes. 2015; 8: 637.

PubMed: https://www.ncbi.nlm.nih.gov/pubmed/26526722

23. Amako K, Takade A. The fine structure of Bacillus subtilis revealed by the rapid-freezing and substitution-fixation method. Microscopy. J Electron Microsc (Tokyo). 1985; 34: 13-17.

PubMed: https://www.ncbi.nlm.nih.gov/pubmed/3932576 